\title{
I mpactos das atividades humanas sobre a dinâmica do fósforo no meio ambiente e seus reflexos na saúde pública
}

\author{
The impact of human activities on the dynamics of phosphorus \\ in the environment and its effect on public health
}

Claudia M aria Gomes de Quevedo ${ }^{1}$

Wanderley da Silva Paganini ${ }^{1}$

${ }^{1}$ FaculdadedeSaúde

Pública da U niversidade de São Paulo. Avenida Doutor Arnaldo 715. 01255-000

São Paulo SP.

claugomes@usp.br
Abstract Phosphorus is a nutrient with finite and non-renewable sources, the speed of exploitation of which is currently far higher than the rates of return to its natural cycle. It is already being predicted that available and known sources will soon be exhausted, with serious and irreversible economic, social and environmental impacts. In this context, this study sets out to present information about the dynamics of phosphorus in the environment, assessing the impacts caused by human activitiesand establishing what actions might contribute to preservation of the nutrient cycle. To contribute to enhanced understanding of the topic, the evolution of data on population density, the number of industries and the extension of cultivated areas in a river basin, was studied over 22 years in relation to concentrations of phosphorus in water and sediment. The Tietê River was used for the case study. The results revealed that the control of domestic effluent, especially the amount of sodium tripolyphosphate (ST PP) used in detergents and soap products, is of major importance for improving water quality, ensuring environmental protection and safeguarding publichealth. Key words Phosphorus, Urbanization, D etergents, Water quality, Public health
Resumo 0 fósforo é um nutriente com fontes finitas enão renováveis, cuja vel ocidade de exploração é atualmente muito superior às suas taxas de retorno ao seu ciclo natural, sendo que já existem previsões a respeito de um provável colapso nas suas fontes disponíveis e conhecidas, com impactos econômicos, sociais e ambientais graves e irre versíveis. Diante desse cenário, o presente trabaIho busca apresentar informações sobre a dinâmica do fósforo no meio ambiente, avaliando os impactoscausados pelas atividades humanas everificando as ações que podem auxiliar na preservação do ciclo do nutriente. Visando contribuir para uma melhor visualização do assunto, foi analisada a evolução dos dados relativos à concentração populacional, número deindustriais e extensão dasáre as cultivadas em uma bacia hidrográfica, em relação às concentrações de fósforo nos compartimentos água e sedimento, ao longo de 22 anos. Para tanto, utilizou-se o rio Tietê como estudo de caso. Os resultados obtidos indicam que o controle das fontes domésticas, principalmente da quantidade de tripolifosfato de sódio (STPP) utilizada nos de tergentes, é de grande importância para a melhoria da qualidade das áquas, proteção ao meio ambiente e garantia da saúde pública.

Palavras-chave Fósforo, U rbanização, D etergentes, Q ualidade das águas, Saúde pública 
Introdução

Como parte importante dos ácidos nucleicos e dos conjuntos de transferência de energia, o fósforo torna-se um elemento vital para o funcionamento dos sistemas biológicos de todos os organismos vivos. 0 fósforo é, também, maté ria-prima de diversos produtos industrializados utilizados em larga escala pelo homem, como éo caso dos fertilizantes e dos detergentes em pó.

A ação predadora do homem sobre os animais marinhos, aliada à crescente exploração das fontes de fósforo pela mineração, pela ocupação desordenada do solo, pelo desmatamento e, principalmente, pelo incremento das atividades industrial e agrícola, tem ocasionado a alteração da dinâmica desse nutriente no meio ambiente.

Assim, estima-se que as taxas de retorno do fósforo ao seu ciclo biogeoquímico estejam cada vez mais reduzidas em comparação com as suas perdas, com impactos na disponibilidadedesuas fontes naturais e na qualidade das águas, em de corrência dos processos de eutrofização. Calcula-se que de 2 milhões de toneladas de fósforo que são produzidas atualmente, somente cerca de 60 mil retornam ao meio de origem ${ }^{1-3}$.

Preocupados com essas questões, diversos países passaram a discutir as formas de controle, através da aplicação de medidas preventivas, partindo inicialmente para a redução da quantidade de tripolifosfato de sódio (STPP) presente nos detergentes. Nesse sentido, diversas localidades, como Suíça, Alemanha, H olanda e Japão, deixaram de comercializar os detergentes fosfatados desde a década de 1980. Passou-se a discutir também, de forma mais intensa, a necessidade de serem adotadas outras medidas de gerenciamento econtrole, envolvendo o monitoramento do lançamento de esgotos, bem como a meIhoria gradativa e planejada na eficiência dos sistemas de tratamento, a fiscalização dos despejos industriais e a adoção de processos de produção agrícola mais controlados e sustentáveis, levando-se em conta as alternativas mais adequadas para a reciclagem do nutriente.

O conjunto dessas ações tem sido considerado fundamental para a melhoria da qualidade das águas, para a preservação do ciclo natural do fósforo e para a garantia da saúde pública, uma vez quesetrata de um nutrienteindispensável à produção biológica, equenão pode ser substituído por qualquer outro elemento naturalmente disponível ou sintetizado pelo homem.

\section{As Atividades Humanas e o Ciclo do Fósforo}

Ao contrário do nitrogênio, cujo reservatório é o $a r$, a fonte de fósforo na natureza é a litosfera. Sua liberação natural ocorre principalmente por meio das erosões do solo, num processo lento em que parte do fosfato é transportada para a hidrosfera, meio onde pode sedimentar-se ou ser utilizado pelos seres vivos. 0 retorno do fósforo sedimentado nos mares ocorre também muito lentamente, principalmenteatravés dos peixes e aves marinhas, ${ }^{1,2,4}$.

0 transporte através das águas é parte fundamental do ciclo do fósforo, correspondendo à forma predominante com que o fosfato se move através do meio ambiente; seu comportamento em rios e reservatórios relaciona-se diretamente com o nível e intensidade das contribuições, sejam elas naturais ou artificiais.

As fontes naturais estão relacionadas principalmente com as cargas difusas, devido aos processos erosivos da bacia de contribuição, à decomposição dos organismos aquáticos e dos vegetais que compõem as matas ciliares, ao assoreamento do corpo d'água, ao intemperismo das rochas e à intensidade das trocas ocorridas entre o sedimento e a coluna d'água.

Em bacias mais desenvolvidas economicamentee com grande concentração populacional, o aporte de fósforo nas águas está mais relacionado com as fontes denominadas artificiais ou antrópicas, que são decorrentes da ação do homem. N esses locais, apesar de ocorrer a contribuição dos processos naturais, estima-se que as fontes artificiais sejam sensivelmente mais importantese, dentreelas, destacam-seo escoamento superficial deáreas cultivadas, os efluentesindustriais e, principalmente, o lançamento de esgotos domésticos ${ }^{4-7}$.

\section{Presença de Fósforo \\ nos Esgotos Domésticos}

Nos esgotos domésticos, o fósforo aparece na forma de compostos orgânicos, como por exemplo, as proteínas, e em compostos minerais, principalmente polifosfatos e ortofosfatos, que tem origem em produtos sintetizados. Os polifosfatos representam, principalmente, os despejos com detergentes sintéticos.

Os esgotos domésticos possuem concentração de fósforo da ordem de 4 a $50 \mathrm{mg} / \mathrm{L}$, a partir de uma produção diária de 1 a $3 \mathrm{~g}$ por pessoa. No Brasil, a contribuição per capita diária defós- 
foro nos esgotos domésticos é de 0,7 a 2,5 g e a concentração típica desse nutriente situa-se na faixa de 4 a $15 \mathrm{mg} / \mathrm{L}$. D esse total, a fração inorgânica, que pode representada basicamente pela utilização de detergentes, fica compreen dida entre 3 a $9 \mathrm{mg} / \mathrm{L}^{3,5-8}$.

Nos detergentes, o fósforo tem a função de builder, ou agente sequestrante, formando complexos estáveis e solúveis com os cátions causadores da dureza na água, como o cálcio e o magnésio. Proporcionam alcalinidade à solução, facilitando a ação do agente tensoativo, auxiliando na limpeza e na formação de espumas. Um detergenteem pó deuso comercial típico queutiliza fosfato como builder, contém, em média, 50\% do peso do produto em tripolifosfato de sódio (STPP), sendo o restante composto por surfactantes, carga, sais inorgânicos, perfume, branqueador óptico, agentes antideposição eenzimas. De forma geral, nos locais onde há utilização doméstica de detergentes compostos por STPP, considera-se que $50 \%$ a $80 \%$ do fósforo presente nos esgotos tem essa origem ${ }^{9-11}$.

As discussões acerca da relação entre o comprometimento da qualidade das águas superficiais, o lançamento de esgotos domésticos e a utilização de detergentes fosfatados tiveram início na década de 1960 e, a partir da década de 1970, diversas localidades da Europa e dos Estados Unidos passaram a restringir o uso de STPP nesses produtos. Posteriormente, já na década de 1990, esses países passaram a adotar critérios para remoção de fósforo em sistemas de tratamento deesgotos, estabelecendo prioridades para direcionamento dos investimentos ${ }^{11}$.

A Comunidade Europeia, por exemplo, através da Council Directivenํ271, de 21 de maio de 1991, estabeleceu um critério de prazos para adequação ou implantação de sistemas de tratamento dos esgotos sanitários, considerando o porte do município esua localização em relação às áre as consideradas sensíveis ou suscetíveis à eutrofização. Quando não justificada a instal ação deum sistema tratamento mais avançado, através dos denominados processos terciários, seja pela inexistência de motivação ambiental ou pelos altos custos, a Diretiva permite a implantação de sistemas de tratamento em nível secundário. Para municípios de pequeno porte, com menos de 20 mil habitantes, é possível viabilizar sistemas de disposição dos esgotos no solo, garantindo o aumento das taxas de retorno do nutriente ao ciclo, processo denominado por closing the loop ${ }^{12-15}$.

No Brasil, a questão da limitação da carga de fósforo nos detergentes, data do ano de 1978 , quando foi implementada a Resolução Normativa $n=01$, do M inistério da Saúde, que estabeleceu o limite de $15 \%$ em peso de $\mathrm{P}_{2} \mathrm{O}_{5}$ por formulação de detergente. Tal legislação foi revisada em 2005, quando foi editada a Resolução $n=359$, de 29/04/2005, do Conselho Nacional do M eio Ambiente (Conama), que define a redução progressiva de $\mathrm{P}_{2} \mathrm{O}_{5}$, em peso, por formulação, atingindo o limitede $10,99 \%$ a partir do ano de $2008^{16,17}$.

No que se refere à presença de fósforo nos esgotos, a Resolução Conama no 357, de 29/04/ 2005, prevê limites de concentração de fósforo para o corpo d'água de acordo com a sua classe de enquadramento, sendo que não há legislação específica em relação à concentração desse nutriente nos efluentes domésticos e industriai ${ }^{18}$.

No entanto, percebe-se, no país, uma tendência de que as discussões evoluam no sentido de que sejam adotados padrões lineares para lançamento de nutrientes nos esgotos. N esse sentido, não são levadas em conta as diversidades regionais e os diferentes aspectos ambientais, econômicos e sociais envolvidos, como o potencial de eutrofização do corpo d'água, os seus usos previstos e requeridos, a factibilidade de disponibilização e aplicação dos recursos financeiros necessários e as metas para universalização dos serviços de saneamento.

0 alinhamento entre as questões ambientais e de saúde pública da população, item preconizado na Lei 11.445, de 05/01/2007, que estabelece as diretrizes nacionais para o saneamento básico, é considerado um fator fundamental, uma vez que 0 acesso aos serviços de saneamento ea universalização dos níveis de atendimento são considerados itens materiais mínimos necessários à promoção da saúde eà qualidade de vida ${ }^{19,20}$.

\section{Dinâmica do Fósforo e Saúde Pública}

0 fósforo não é um elemento tóxico à saúde dos seres vivos, sendo, ao contrário, essencial à manutenção da vida. A presença deletéria do fósforo no meio ambiente está relacionada com 0 aporte excessivo nas águas. N este caso, o nutriente pode desencadear processos de eutrofização, ou fertilização, ocasionando, por exemplo, proliferação de algas e de outras plantas aquáticas superiores, as macrófitas. Tal situação pode inviabilizar diversos usos, comprometendo, inclusive, sua utilização para abastecimento público.

De acordo com Tundisi ${ }^{21}$, o aumento nos níveis de eutrofização pode acarretar a diminuição da quantidade e da qualidade da água e a perda da capacidade de sustentabilidade do sistema, 
com consequente aumento do nível de toxicidade e deterioração da saúde humana.

Em um ambiente eutrofizado, a floração de cianobactérias é especial mente perigosa, pois diversas espécies liberam toxinas, causando sérios prejuízos às águas utilizadas para abastecimento público. Foi a presença delas que provocou a morte de 40 pacientes de uma clínica de hemodiálise de Caruaru, em Pernambuco, no ano de $1996^{22}$.

Atualmente, 0 aumento no ritmo deexploração das fontes de fósforo para utilização em produtos industrializados, além de agravar a situação de eutrofização das águas, tem provocado discussões quanto à escassez do nutriente. Ao longo das últimas décadas, diversas previsões vêm sendo efetuadas a respeito do possível esgotamento das fontes de naturais de fósforo no meio ambiente, num curto a médio espaço de tempo, com reflexos graves à saúde pública, uma vez que o fósforo não pode ser substituído por nenhum outro elemento químico disponível na natureza ou sintetizado pelo homem.

De acordo com Cordell ${ }^{15}$, no ritmo atual de exploração e a partir do crescimento populacional previsto, calcula-se que as reservas de rocha fosfática conhecidas e exploráveis estejam extintas no período de 50 a 100 anos.

As preocupações quanto à provável escassez das reservas de fósforo no meio ambiente e a inexistência de qualquer outro elemento que 0 substitua nos processos biológicos e na produção vegetal são abordadas por $\mathrm{M}$ alavolta ${ }^{23}$, da seguinte forma:

O limite de crescimento da humanidade não será ditado pelo esgotamento dos minerais estraté gicos ou pelo das reservas de combustíveis fósseis como pretende ou pretendia o Clube de Roma, pois para esses há alternativas técnicas e econômicas.

A humanidade poderá crescer enquanto houver no solo fósforo para ser aproveitado eenquanto o homem puder transferir esse elemento da litosfera para a biosfera servindo como comida insubstituível para as plantas e para os animais, pois o fósforo évida e sem ele teríamos um planeta silencioso.

Assim, tomam corpo as discussões inerentes ao paradoxo existente entre a essencialidade do nutriente e a sua disponibilidade limitada na natureza. Intensificam-seas discussões relativas aos impactos das atividades do homem sobre o seu ciclo, buscando-se alternativas para melhoria da qualidade das águas e garantia da saúde pública, promovendo-se a sua reciclagem e preservação ambiental, de forma sustentável.

\section{M etodologia}

Para desenvolvimento do trabalho, foram inicialmentelevantadas informações sobreo elemento químico fósforo, seu ciclo biogeoquímico, comportamento no solo e nas águas, bem como, sobre as atividades antrópicas que contribuem para o seu aporte em rios e reservatórios.

Visando avaliar o impacto dessas atividades sobre a ciclagem do nutriente, oferecendo hipóteses quanto às suas princi pais fontes nas águas, foi efetuada uma análise da evolução dos dados relativos à concentração populacional, número de industrias e extensão das áreas cultivadas em uma bacia hidrográfica, comparando-os com informações relativas às concentrações de fósforo nos compartimentos água e sedimento.

Para realização dessa análise, efetuou-se um estudo de caso sobre o rio Tietê. Justifica-se a escol ha deste devido a al guns fatores que lheconferem características particulares, como a diversidade de formas de uso e ocupação da bacia, decorrentes da elevada extensão territorial, e os intensos contrastes relacionados com a qualidade daságuas. Justifica-seainda, pela existência de uma sequência de grandes represas ao longo do seu curso, característica que lhe altera o regime hídrico, contribuindo para a redução da velocidade das águas e favorecendo a precipitação do nutriente.

Para tanto, foram levantadas informações sobre as atividades urbana e agrícola desenvolvidas no decorrer de 22 anos, entre 1986 e 2007, nas 6 Unidades de Gerenciamento dos Recursos Hídricos(UGRHI) pertencentes ao rio Tietê: Alto Tietê, Piracicaba/Capivari/Jundiaí, Tietê/Sorocaba, Tietê/Jacaré, Tietê/Batal ha e Baixo Tietê.

Em relação à atividade urbana, foram compilados dados sobre a população total e a urbana, por município, disponibilizados pela Fundação Sistema N acional de Análise de Dados (Seade), através do Sistema de Informações dos Municípios Paulistas (IM P), e informações sobre o número de indústrias, fornecidas pela Companhia de Tecnologia de Saneamento Ambiental (Cetesb), a partir do Sistema de Informações sobre Fontes de Poluição (Sipol) 24,25.

Para verificação da atividade agrícola, foram utilizadas informações sobre a extensão das áreas cultivadas, obtidas junto à Coordenadoria de Assistência Técnica Integral (Cati), através do Levantamento das Unidades de Produção Agropecuária (Lupa) ${ }^{26,27 .}$.

As informações relativas à concentração de fósforo na coluna d'água e sedimento foram fun- 
damentadas a partir de dados secundários oriundos da Rede de Monitoramento da Qualidade das Águas Interiores do Estado de São Paulo, operacionalizada pela Cetesb, registrados e disponibilizados anualmentenos Relatórios de Qualidade das Águas Interiores. Foram analisados 26 pontos demonitoramento localizados no caudal do rio Tietê, ao longo das diferentes U GRHIs, sendo 22 pontos relativos à coluna d'água e 4 ao compartimento sedimento.

No que se refere ao compartimento água, o período dedados estudado é de 22 anos, compreendido entre 1986 e 2007 e, em relação ao sedimento, o estudo é efetuado para os anos de 2004 e 2005, uma vez que a análise do parâmetro fósforo total no sedimento foi efetuada e disponibilizada pela Cetesb somente para esse período ${ }^{28}$.

\section{ResultadoseDiscussão}

A bacia do rio Tietê possui atualmente mais de 28,7 milhões de habitantes, o que corresponde a $70,6 \%$ da população total do Estado de São Paulo. No período de 1986 a 2007, o número de habitantes da bacia foi ampliado em cerca de 8,7 milhões de habitantes, dos quais, mais de 5,3 milhões localizam-seU GRHI Alto Tietê. Em termos percentuais, no entanto, a maior taxa de crescimento médio anual ocorreu nas UGRHIs Piracicaba/Capivari/Jundiaí e Tietê/Sorocaba, com $2,73 \%$ e $3,07 \%$ ao ano, respectivamente.

No que se refere ao número de indústrias, a bacia do Tietê apresentou um crescimento de 214\% entre 1995 e 2008, destacando-se os segmentos produtos de metal, máquinas de escritório einformática, material médico-hospitalar, máquinas e equi pamentos, montadora deautos e material eletrônico. 0 maior crescimento percentual, com uma expansão de $795 \%$, se dá no Tietê/Jacaré, U GRH I classificada na categoria "em industrialização" através da Lei 9.034/94.

Não obstante, no que se refere a valores absolutos, a U GRHI Alto Tietê concentrou a instalação de 34 mil novas unidades no período de 13 anos, o que corresponde a cerca de $56 \%$ do crescimento verificado em toda a bacia. Apesar de serem apresentados os dados numéricos, a influência qualitativa da atividade industrial sobre o comportamento do fósforo não foi abordada neste trabalho, uma vez que não se dispõe das vazões e das características dos efluentes, ou seja, das respectivas cargas.

Em relação às áreas agricultáveis, a bacia do Tietêapresentou um crescimento decerca de $24 \%$ no período de 1998 e 2008. No Baixo Tietê, onde se encontra a maior extensão deárea cultivada da bacia do Tietê, de mais de 1,5 milhões deha, podese estimar quequase $92 \%$ do território daUGRH I é atualmente ocupado pela atividade agrícola.

$\mathrm{Na}$ Figura 1 pode-se observar o comparativo percentual da população total, número deindústrias e extensão das áreas agricultáveis das U GRHIs do Tietêno ano de 2008, comparativamente à somatória total da bacia do Tietê.

Quanto à presença de fósforo na coluna d'água, os pontos de monitoramento localizadosna U GRHI Alto Tietêapresentaram uma tendência de aumento nas concentrações do nutriente durante o período de 22 anos, situação que se repete nos pontos situados nas U GR Is Is Piracicaba/Capivari/Jundiaí e Tietê/Sorocaba. $\mathrm{Na}$ porção média e inferior do Reservatório de Barra Bonita, apesar do comportamento geral de aumento nas concentrações de fósforo, percebese que os valores são mais reduzidos, comparativamente aos pontos situados a montante.

A partir dasU GRHIs Tietê/Jacarée Tietê/Batal ha, verifica-se uma tendência de estabilização relativa das concentrações médias do nutriente, com redução na U GRHI Baixo Tietê. A Figura 2, a seguir, apresenta as concentrações de fósforo observadas nas bacias do Tietê através das médias quinquenais relativas ao período compreendido entre os anos de 1986 a 2007.

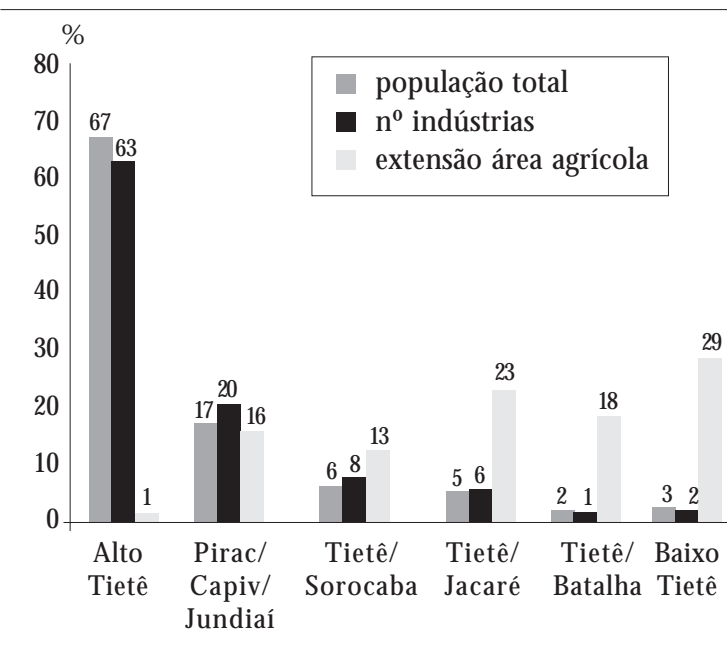

Figura 1. Situação atual das variáveis de população total, número de indústrias e extensão das áreas cultivas, por U GRHI, em termos percentuais, em relação ao total da bacia do Tietê. 
No que se refere ao compartimento sedimento, apesar da disponibilidade de dados somente para os anos de 2004 e 2005, é possível verificar que o ponto demonitoramento TIPI 04850, localizado na U GRHI Tietê/Sorocaba, na porção inferior do Reservatório de BarraBonita, tendea apresentar concentrações de fósforo mais el evadas.

Avaliando-se os dados graficamente, é possível verificar que a partir do ponto em que as concentrações de fósforo na U GRHI Tietê/Sorocaba encontram-se mais baixas na coluna d'água, ao longo do percurso do rio, a concentração do nutriente do sedimento está mais el evada. Tal situa- ção, aliada aos dados sobre as concentrações de fósforo na coluna d'água, permite inferir queesse resultado pode ser decorrente das taxas de precipitação do nutrientequeélançado no corpo d'água em elevadas quantidades nos pontos a montante, principal mentena U GRHI Alto Tietê, aliada a alguns fatores como aumento das vazões, diminuição da velocidade das águas e aumento do tempo de deten ção. 0 comportamento da média de fósforo nos anos 2004 e 2005, na coluna d'água e no sedimento, pode ser verificado na Figura 3.

Comparando-se as variáveis população urbana, número de indústrias, e extensão das áreas

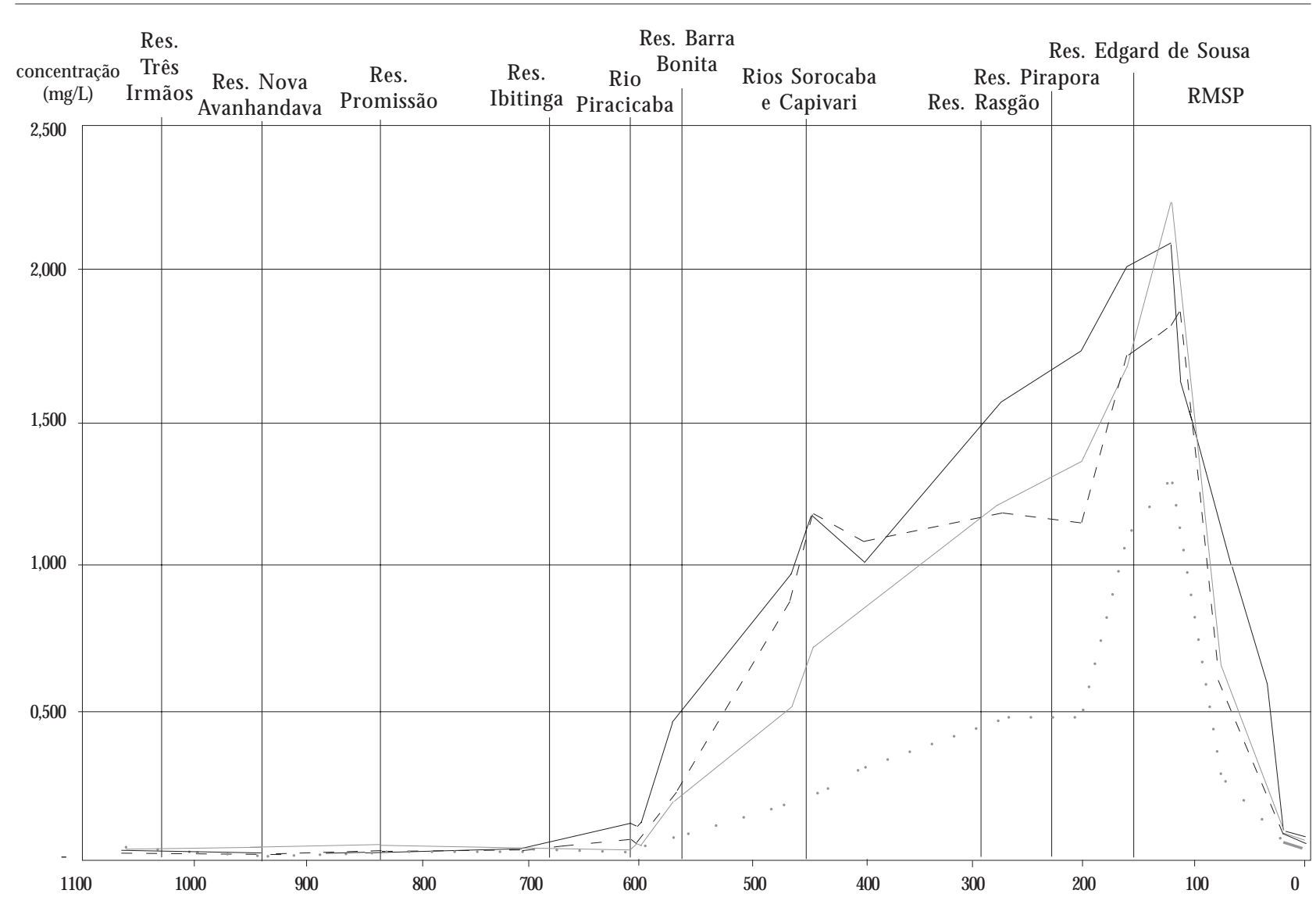

Distância a partir da nascente (km) 
Sedimento

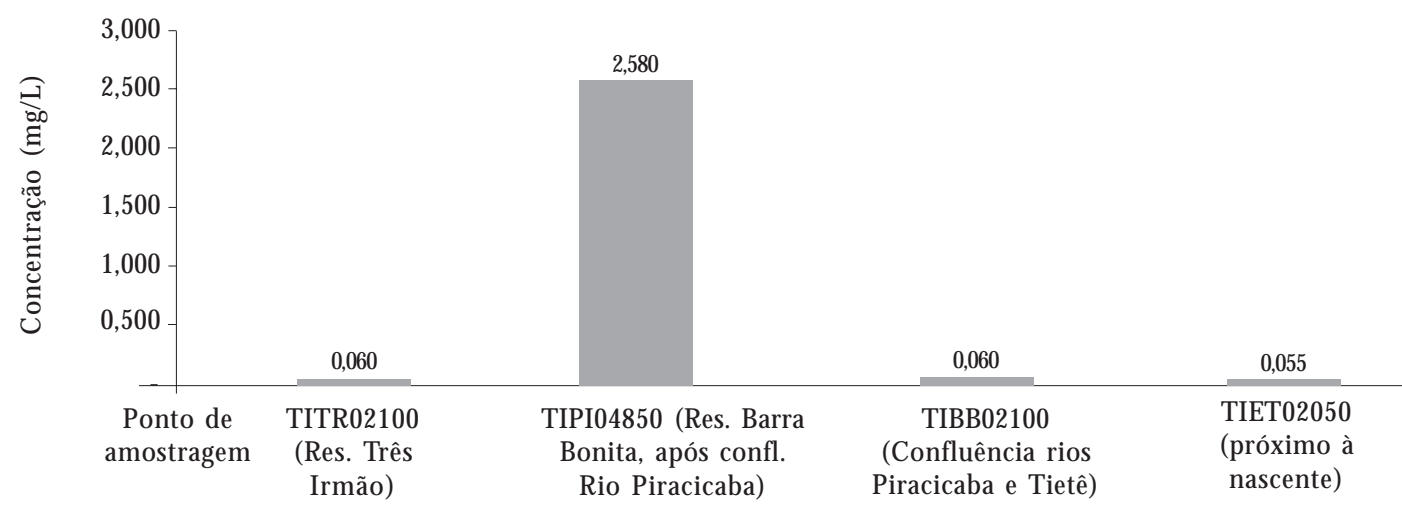

Água

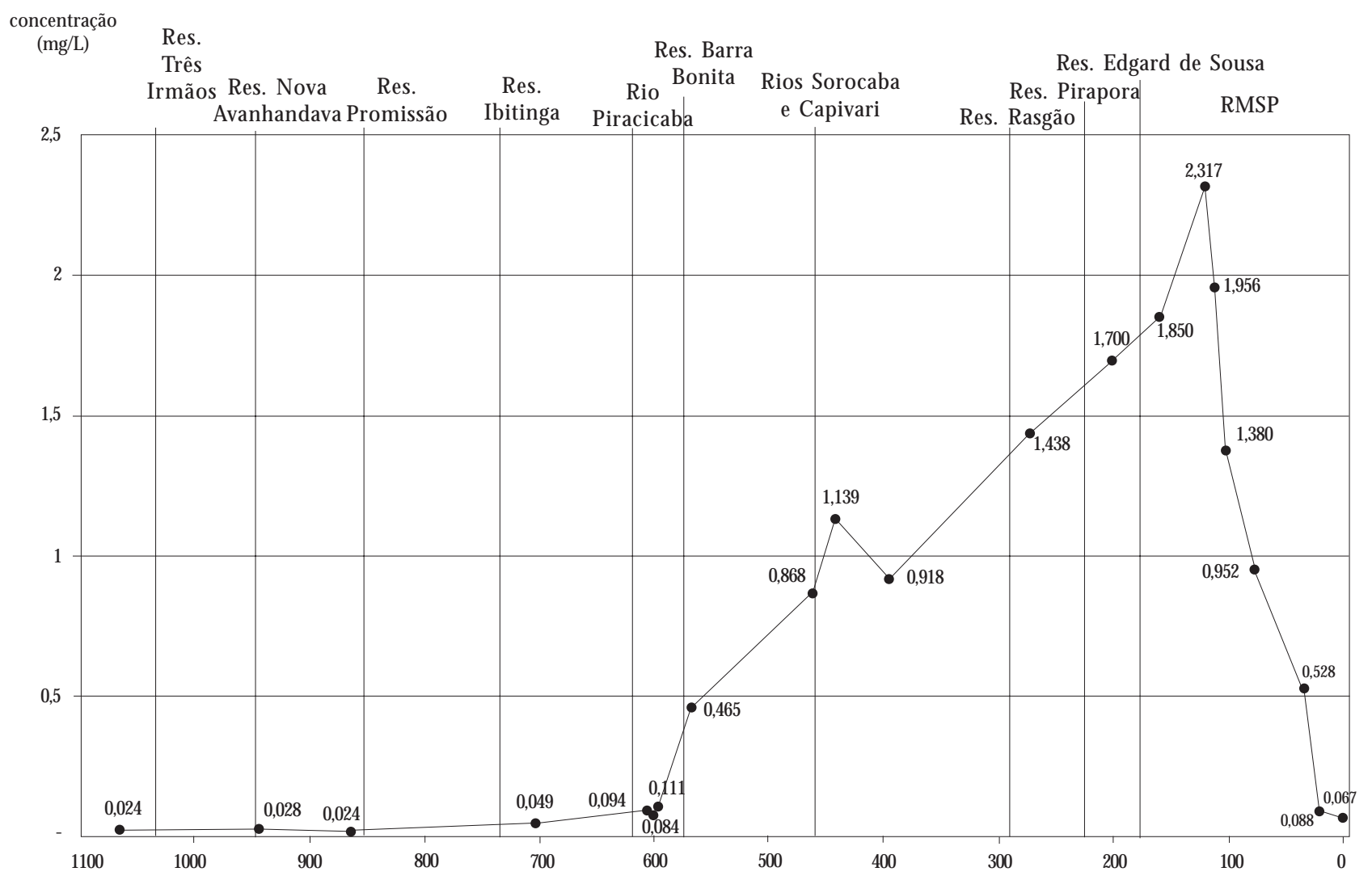

Distância a partir da nascente $(\mathrm{km})$

Figura 3. Concentração de fósforo na coluna d'água e no sedimento, em mg/L, conforme Relatório de Qualidade de Águas I nteriores da Cetesb - M édia dos anos 2004 e 2005. 
agricultáveis com os dados relativos à concentração de fósforo na coluna d'água, é possível verificar que os níveis de fósforo tendem a ser mais el evados nas U GRHIs com maior concentração populacional. Tal comparação pode ser visualizada na Figura 4.
Pelos dados apresentados é possível identificar que a concentração média de fósforo nas águas tende a ser maior nas UGRHIs Alto Tietê, Piracicaba/Capivari/Jundiaí e Tietê/Sorocaba, onde houve uma ampliação de 11,3 milhões de habitantes no período de 22 anos. N esses locais, a
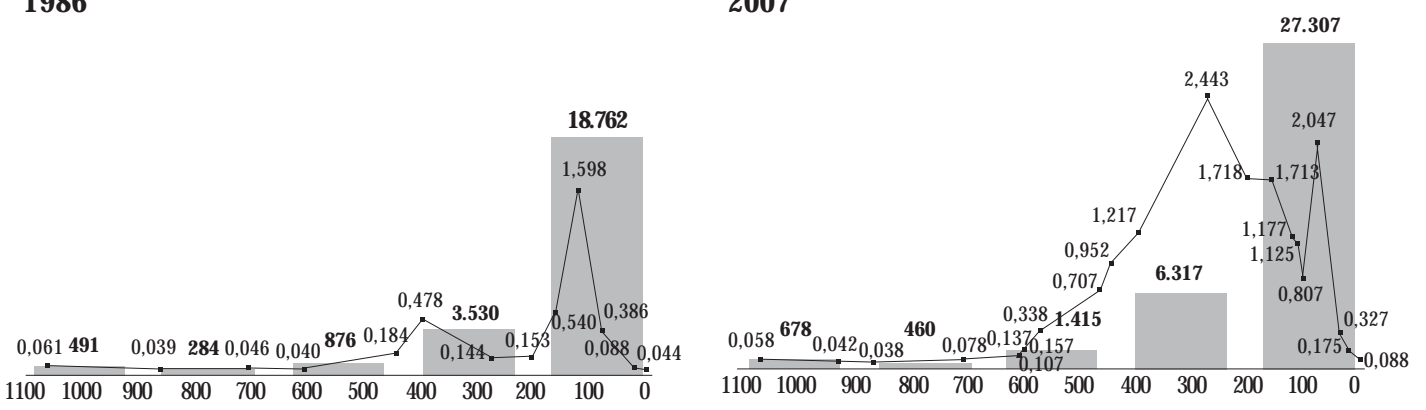

1995

2008
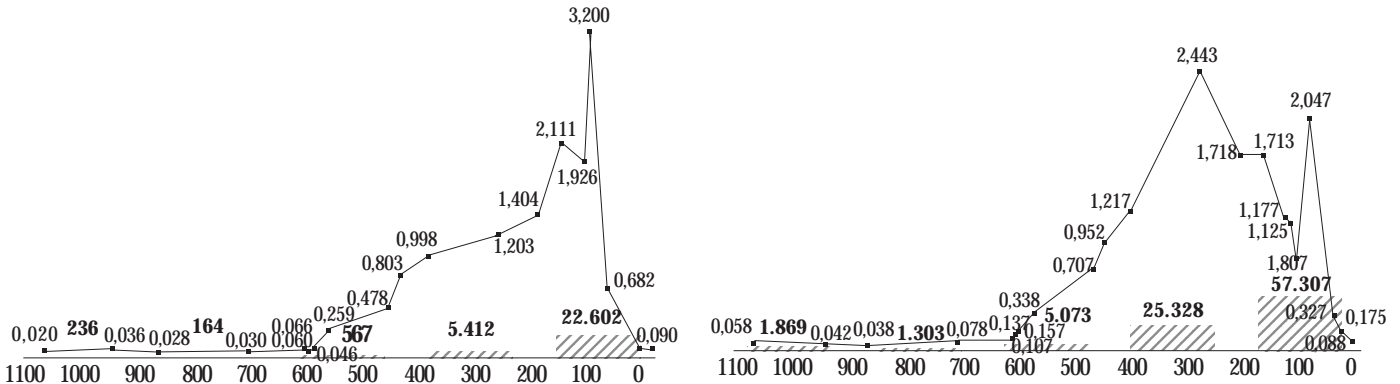

1998

2008
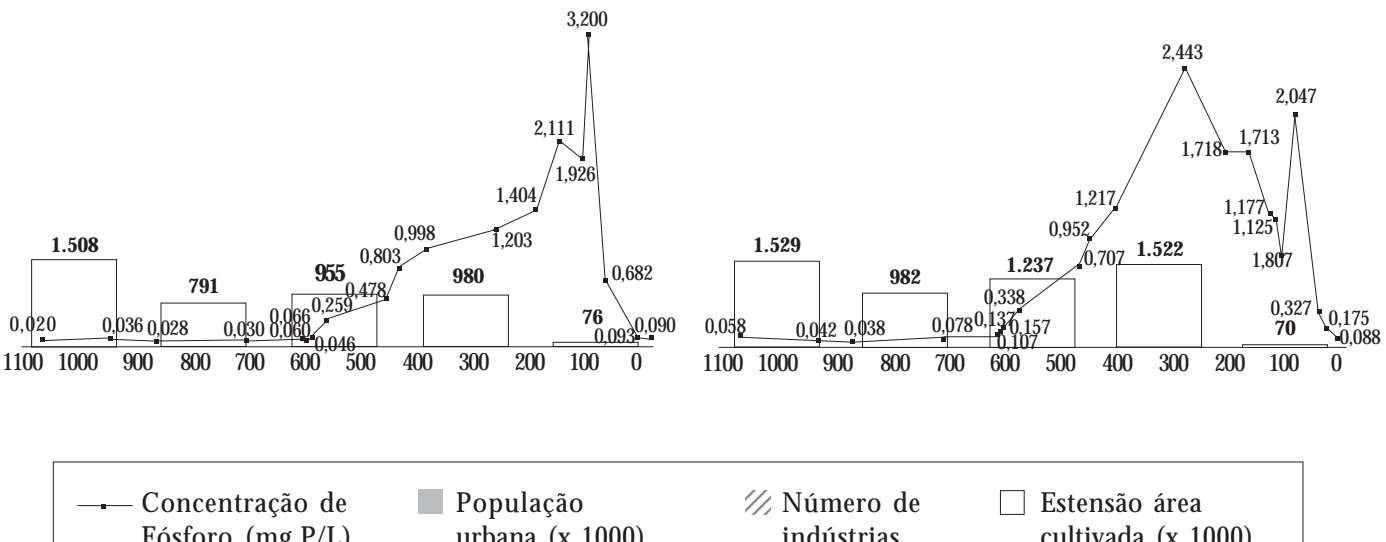

População
urbana (x 1000)

Y), Número de

indústrias

Estensão área

cultivada (x 1000)

Figura 4. Comparação dos dados relativos à populacão total, à população urbana, ao número de indústrias e à extensão das áreas cultivadas na bacia do rio Tietê, em relação à concentração de fósforo na coluna d'água na, entre os anos de 1986 e 2007. 
concentração média de fósforo nas águas foi alterada de 0,399 mg/L em 1986 para 0,945 mg/L em 2007. Nas U GRHIs Tietê/Jacaré, Tietê/Batalha e Baixo Tietê, que concentram atual mente $71 \%$ das áreas cultivadas da bacia, a concentração média de fósforo foi alterada de 0,046 mg/L em 1986 para $0,065 \mathrm{mg} / \mathrm{L}$ em 2007. N o Baixo Tietê, inclusive, que possui atualmente mais de 1,5 milhões de ha de áreas agricultáveis, a concentração média de fósforo apresentou uma redução de $0,050 \mathrm{mg} /$ L em 1986 para 0,046 mg/L em 2007.

Efetuando-se uma estimativa das cargas potenciais de fósforo na bacia decorrentes da atividade urbana, a partir dos dados relativos à população urbana, considerando-se uma contribuição per capita de2,5 g/P/dia, épossível identificar quea contribuição a partir dos esgotos domésticos pode ser estimada atualmente em 68,3 t/dia.

Em relação à atividade agrícola, considerando-se que cada hectare cultivado no Estado de São Paulo, o potencial de perdas de terra seja da ordem de 7,852 t/ha/ano, com concentrações de fósforo de $0,002614 \%$, a carga potencial de fósforo pode ser estimada atualmente em $3 \mathrm{t} / \mathrm{dia}$.

Ainda, considerando-se que da quantidade de fósforo presente nos esgotos domésticos, cerca de $50 \%$ (quantidade mínima) a $80 \%$ (quantidade máxima) é decorrente da utilização de detergentes em pó que contém STPP, é possível estimar que essa fonte seja responsável pelo aporte de 34,1 a 54,6 t/dia defósforo nas águas do Tietê. Desse total, de 23,0 a 36,9 t/dia tem origem na UGRHI Alto Tietê, ou seja, cerca de $33,8 \%$ a 54,0\% do fósforo presente nas águas do Tietê tem origem pela utilização de detergentes fosfatados na U GRHI Alto Tietê.

Caso a totalidade das formulações dos detergentes em pó para uso doméstico comerciali- zados no Brasil esteja obedecendo os limites de STPP propostos pela Resolução Conama no 359/ 05 , atendendo plenamente as expectativas estabelecidas, a redução no aporte de fósforo nas águas do rio Tietê desde 0 ano de 2008 seria da ordem de 10,2 a 16,4t/dia, o queéainda considerada uma redução muito conservadora, uma vez que a quantidade de fósforo lançada nas suas águas através dos esgotos domésticos em decorrência do uso de detergentes poderia ser estimada atualmente, ainda, em 23,9 a 38,2 t/dia.

$\mathrm{Na}$ Tabela 1, a seguir, pode-se visualizar um comparativo entrea contribuição potencial total de fósforo na bacia do Tietê, bem como as contribuições estimadas deSTPP antes eapós a aplicação da Resolução Conama no 359/05.

\section{Conclusão}

A partir dos dados levantados no decorrer do presente trabalho, considerando-se as informações avaliadas no levantamento bibliográfico, bem como os dados obtidos a partir do estudo de caso, pode-se verificar que o impacto da atividade urbana para o aumento da concentração de fósforo nas águas é bastante elevado, comparativamente à atividade agrícola. Pode-se verificar também, a magnitude e a inquestionável contribuição dos detergentes para configuração desse cenário.

O controle do aporte de fósforo nas águas a partir da atuação nas fontes oriundas da atividade urbana, principalmente pela limitação da presença de tripolifosfato de sódio (STPP) nos detergentes, demonstra ser de grande importância para a melhoria da qualidade das águas e para a preservação do ciclo do nutriente. Isto porque, além de auxiliar na redução do aporte do princi-

Tabela 1. Cargas atuais estimadas de fósforo nas águas do Tietê, por UGRHI, em decorrência do uso de detergentes contendo STPP, em t/dia.

\begin{tabular}{|c|c|c|c|c|c|}
\hline \multirow[b]{2}{*}{ UGRHI } & \multirow[b]{2}{*}{$\begin{array}{l}\text { Total nos Esgotos } \\
\text { Domésticos (t/dia) }\end{array}$} & \multicolumn{2}{|c|}{ Antes CONAMA 359/05 } & \multicolumn{2}{|c|}{ Após CONAMA 359/05 } \\
\hline & & $\begin{array}{l}\text { Mínimo } \\
(50 \%)\end{array}$ & $\begin{array}{l}\text { Máximo } \\
(80 \%)\end{array}$ & $\begin{array}{l}\text { Mínimo } \\
(50 \%)\end{array}$ & $\begin{array}{l}\text { Máximo } \\
(80 \%)\end{array}$ \\
\hline Alto Tietê & 46,10 & 23,05 & 36,88 & 16,13 & 25,81 \\
\hline Piracicaba/Capivari/J undiaí & 11,73 & 5,86 & 9,38 & 4,11 & 6,57 \\
\hline Tietê/Sorocaba & 4,06 & 2,03 & 3,25 & 1,42 & 2,28 \\
\hline Tietê/J acaré & 3,54 & 1,77 & 2,83 & 1,24 & 1,98 \\
\hline Tietê/Batalha & 1,15 & 0,57 & 0,92 & 0,40 & 0,64 \\
\hline Baixo Tietê & 1,69 & 0,88 & 1,36 & 0,59 & 0,95 \\
\hline Total da Bacia do Tietê & 68,27 & 34,13 & 54,61 & 23.894 & 38,23 \\
\hline
\end{tabular}


pal nutrientelimitante do crescimento biológico em um ambiente aquático, a redução da presença de fósforo nesses produtos pode auxiliar na diminuição das suas taxas deexploração no meio ambiente, contribuindo para sua conservação.

A evolução nas ferramentas de controle do aporte de fósforo nas águas ér relevante, também, para a garantia da saúde pública, uma vez que pode contribuir para a redução dos níveis de eutrofização das águas. N esse sentido, o controle das fontes de fósforo em áreas urbanas demonstra ser uma alternativa mais simples do que a implantação generalizada dossistemas mais avançados de tratamento dos esgotos domésticos, os denominados sistemas terciários.

0 estabelecimento de padrões de qualidade para os corpos receptores é uma ferramenta imprescindível para a manutenção da qualidade dos corpos d'água. Já o estabelecimento de limites de lançamento, de forma linear, considerando-se somentea obrigatoriedadee a abrangência nacional da legislação, pode trazer consequências indesejáveis e onerosas, pois os sistemas terciários de tratamento de esgotos possuem elevados custos de implantação, operação e manutenção, os quais são, muitas vezes, desnecessários para 0 momento, se consideradas as condições de diluição e uso dos corpos d'água receptores.

Além disso, o estabelecimento de metas graduais e progressivas para melhoria da qualidade das águas, a serem atendidas ao longo do tempo, torna-se fundamental para a viabilização de melhorias nos sistemas de saneamento. Permitese, assim, promover a racionalização na aplicação dos recursos financeiros, de acordo com a realidade sócio-econômica brasileira, alinhando as questões ambientais à necessidade de melhoria das condições da saúde pública da popula- ção. Tal prerrogativa, inclusive, encontra-se preconizada na Lei $11.445 / 2007$, que estabelece as diretrizes nacionais para o saneamento básico.

Ou seja, a exemplo de outros países, necessita-se de uma evolução nas ferramentas para controle das fontes urbanas de fósforo, fiscalização e acompanhamento das medidas implementadas, a ponto de banir a presença de STPP nos detergentes, para depois serem sugeridas metodologias para implantação de sistemas mais avançados de tratamento de esgotos, de forma gradual e criteriosa.

Em relação à atividade agrícola, não obstante sua contribuição para o aporte de fósforo nas águas seja mais reduzido, comparativamente à atividade urbana, merecem ser planejadas e adotadas ações voltadas para redução dos seus impactos sobre a dinâmica do fósforo no meio ambiente, principal menteno quese refere ao gerenciamento do uso defertilizantes.

Assim, a questão da dinâmica do fósforo no meio ambiente deve ser entendida e estudada de forma integrada e sistêmica, levando-se em conta não somente as alternativas técnicas para a redução do seu aporte nos rios e reservatórios, como forma de buscar controlar os processos de eutrofização emelhorar a qualidade das águas, mas também as metodologias que busquem a conservação e proteção do meio ambiente e a garantia da saúde pública.

Trata-se, portanto, da efetiva gestão ambiental em prol da qualidade de vida das futuras gerações, visando a preservação de um nutriente que não pode ser substituído nos processos biológicos por nenhum outro elemento naturalmente disponível ou sintetizado pelo homem, ecujas fontes, finitas e não renováveis, encontram-se alarmantemente próximas da exaustão.

\section{Colaboradores}

CM G Quevedo e WS Paganini participaram igualmente de todas as etapas de elaboração do artigo. 


\section{Referências}

1. Branco SM, Rocha AA. Elementos de ciência do ambiente. 2a ed. São Paulo: Cetesb/ASC etesb; 1987.

2. Derísio JC. Introdução ao controle da poluição ambiental. 2a ed. São Paulo: Signus Editora; 2000.

3. Braga $B$, Hespanhol I, Conejo JGL, Barros MTL, Spencer M, Porto M, Nucci N, Juliano N, Eiger S. Introdução à engenharia ambiental. São Paulo: Prentice Hall; 2002.

4. Esteves FA. Fundamentos de limnologia. Rio de Janeiro: FINEP; 1988.

5. Chave PA. Legal and regulatory instruments. In: Helmer R, Hespanhol I, organizadores. Water poIlution control: a guide to the use of water quality management principles. London: WHO/UNEP; 1997.

6. Von Sperling M. Introdução à qualidade das águas e ao tratamento de esgotos. 3a ed. Belo Horizonte: DESA/UFM G; 2005. 1 v.

7. Pivelli RP, Kato MT. Qualidade das águas e poluição: aspectos físico-químicos. São Paulo: ABES; 2005.

8. M etcalf $L$, Eddy H P. Wastewater engineering: treatment and reuse. $4^{\text {th }}$ ed. Singapore: M cGraw-Hill Inc.; 2003.

9. Devey $D$ G, Harkness $N$. The significance of manmade sources of phosphorus: detergents and sewage. In: Jenkins SH, I ves K J, organizadores. Phosphorus in fresh water and the marine environment. $2^{\text {th }}$ ed. London: Pergamon Press Officers; 1975. 2 v.

10. Chorus I, Bartran J, organizadores. Toxic cyanobacteria in water: a guide to their public health consequences, monitoring and management. London: WHO/UNEP; 1999.

11. Glennie EB, Littlejohn C, Gendebien A, Hayes A, Palfrey $R$, Sivil D, Wright K. Phosphates and alternative detergent builders: final report. Wiltshire: EU Environment Directorate; 2002.

12. European Community. Council Directive no 271, of $21 \mathrm{M}$ ay 1991 . Concerning urban waste water treatment [diretiva na internet]. [acessado 2009 fev 20]. Disponível em: http://eur-lex.europa.eu.

13. Centre Européen d'Estudes des Polyphosphates (CEEP). [homepage na internet]. Bruxelas; 2009. [acessado 2008 dez 15]. Disponível em: http://http:/ /www.ceep-phosphates.org

14. Lloyd J. The nutrient cycle: closing the loop [documento na internet]. Reino Unido: Green Alliance; 2007. [acessado 2008 dez 15]. Disponível em: http://www.green-alliance.org.uk

15. Cordell D. The story of phosphorous: missing global governance of a critical resource [documento na internet]. Suécia: Global Phosphorus Research Initiative; 2008 [acessado 2008 dez 15]. Disponível em: http://phosphorusfutures.net

16. Brasil. M inistério da Saúde. Instrução Normativa no 01 , de 29 de novembro de 1978. Aprova as normas a serem obedecidas pelos detergentes e seus congêneres [documento na internet]. [acessado 2009 jan 10]. Disponível em: http://www.anvisa.gov.br/ legis/resol/01_78.htm>
17. Brasil. Conselho Nacional do M eio Ambiente. Ministério do M eio Ambiente. Resolução no 359, de 29 de abril de 2005. Dispõe sobre a regulamentação do teor de fósforo em detergentes em pó para uso em todo o território nacional e dá outras providências [resolução na internet]. [acessado 2009 jan 10]. Disponível em: http://www.mma.gov.br/port/conama/ res/res05/res35905.pdf

18. Brasil. Conselho Nacional do M eio Ambiente. Ministério do M eio Ambiente Resolução no 357, de 17 de março de 2005. Dispõe sobre a classificação dos corpos de água e diretrizes ambientais para o seu enquadramento, bem como estabelece as condições e padrões de lançamento de efluentes, e dá outras providências [documento na internet]. [acessado 2009 jan 10]. Disponível em: http://www.mma. gov.br/port/conama/res/res05/ res35705.pdf>

19. Brasil. Lei no 11.445, de 05 de janeiro de 2007. Estabelece diretrizes nacionais para o saneamento básico e dá outras providências [lei na internet]. [acessado 2008 set 14]. Disponível em: http://www. planalto.gov.br/ccivil_03/_ato2007-2010/2007/lei/ I11445.htm

20. M inayo M CS, Hartz ZM A, Buss PM. Qualidade de vida e saúde: um debate necessário. Cienc Saude Colet 2000; 5(1):7-18.

21. Tundisi JG. Água no século XXI: enfrentando a escassez. São Carlos: RiMa/IIE; 2003.

22. Osorio VKL, Oliveira, W. Polifosfatos em detergentes em pó comerciais. Revista eletrônica Química N ova [periódico na internet]. 2001 [acessado 2008 set 8]; 24(5):700-708. Disponível em: http:// scielo.br/pdf/qn/v24n5/a19v24n5.pdf

23. M alavolta $E$. $O$ fósforo na planta e interações com outros elementos. In: Yamada T, Abdalla SRS, organizadores. Fósforo na agricultura brasileira. Piracicaba: Potafos; 2004.

24. Fundação SEADE. Informações dos M unicípios Paulistas [base de dados na internet]. São Paulo: Secretaria de Economia e Planejamento do Estado de São Paulo. [acessado 2008 dez 8]. Disponível em: http://www.seade.gov.br/ produtos/imp/

25. Companhia de Tecnologia de Saneamento Ambiental (Cetesb). Sistema de Informações sobre Fontes de Poluição. São Paulo; 2009.

26. Coordenadoria de Assistência Técnica Integral (CATI). Levantamento Censitário das Unidades de Produção Agropecuária - Ano 1998. Campinas; 1999.

27. Coordenadoria de Assistência Técnica Integral (CATI). Levantamento Censitário das Unidades de Produção Agropecuária - Ano 2008. Campinas; 2009.

28. Companhia de Tecnologia de Saneamento Ambiental (Cetesb). Relatório de Qualidade de Águas Interiores do Estado de São Paulo: relatório técnico. São PauIo; 1986 a 2007. 22 v.

29. Paganini WS. A identidade de um rio de contrastes: 0 tietê e seus múltiplos usos. São Paulo: Imprensa Oficial do Estado de São Paulo; 2007.

Artigo apresentado em 24/11/2009

Aprovado em 18/12/2009

Versão final apresentada em 06/01/2010 